\title{
Influência de medidas de segurança de trânsito no comportamento dos motoristas
}

\author{
Giovani Bottesini ${ }^{1}$ e Christine Tessele Nodari ${ }^{2}$
}

Resumo: Os acidentes de trânsito são uma das principais causas de morte e invalidez ao redor do mundo, e estima-se que o elemento humano contribua para a ocorrência de mais de $90 \%$ deles, grande parte envolvendo o comportamento dos motoristas. Este artigo apresenta os resultados de uma pesquisa que buscou identificar e classificar medidas de segurança de trânsito conforme sua influência em inibir o cometimento de infrações de trânsito no meio urbano. Para atingir esse objetivo, foram realizadas uma pesquisa qualitativa e uma pesquisa quantitativa. Na primeira, feita por meio de grupos focados, identificaram-se as infrações de trânsito que mais contribuem para os acidentes (embriaguez, excesso de velocidade e avanço de sinal vermelho de semáforo), bem como elementos que auxiliaram na elaboração da pesquisa quantitativa. Esta, por sua vez, consistiu em um questionário autorrelatado aplicado a motoristas de automóvel, no qual verificou-se que as medidas de segurança associadas à restrição de direitos e à possibilidade de ser flagrado pelas autoridades são as que mais influenciam os motoristas a não cometerem infrações.

Palavras-chave: segurança viária; comportamento dos motoristas; infrações de trânsito; medidas de segurança.

\begin{abstract}
Road traffic crashes are one of the leading causes of death and disability worldwide, and the human factor is somehow involved in over $90 \%$ of traffic crashes, with a great contribution of driver behavior. This paper presents the results of a survey aimed at identifying and classifying road safety measures according to their influence on driver behavior, regarding the commitment of traffic offenses in urban environment. In order to reach that goal, a qualitative and a quantitative survey were carried out. The first one applied focus group technique to identify traffic offenses that most contribute the most to road crashes (drunk driving, speeding and red light running), as well as to collect information to help prepare the quantitative survey. The last one consisted in applying a selfreported questionnaire to automobile drivers. Responses suggested that the road safety measures which most influence drivers, so they do not commit traffic offenses, are those related to restrictions to their rights and to the possibility of being caught by authorities.
\end{abstract}

Keywords: road safety; driver behavior; traffic offenses; road safety measures.

\section{INTRODUÇÃO}

Entre os três elementos que compõem o sistema de tráfego (veículo, via e usuário), estima-se que a falha do elemento humano esteja envolvida em $90 \%$ dos acidentes, seja por meio de erros ou de violações à lei (Hoffmann, 2005; Evans, 2004; Shinar, 2007). Evans (2004) atribui ao comportamento do motorista uma maior importância relativa entre os fatores que contribuem para a ocorrência de acidentes, seguido de questões associadas ao tráfego e ao ambiente viário, ao desempenho do motorista e, com menor importância, ao veículo. Essa importância de aspectos relacionados ao comportamento do motorista decorre do fato de que este é capaz de influenciar as demandas do sistema através de escolhas comportamentais, idealmente tornando-as compatíveis com sua capacidade (Tronsmoen, 2008). Cabe destacar a diferença existente entre comportamento e desempenho do motorista. Enquanto o desempenho está associado a tudo o que o motorista está capacitado a fazer, o seu comportamento diz respeito ao que ele escolhe fazer. Dessa forma, o comportamento do motorista assume papel decisivo na segurança viária, uma vez que, mesmo ele sendo capaz de reconhecer um sinal de proibição de ultrapassagem (desempenho do motorista), ele pode optar por ultrapassar

\footnotetext{
${ }^{1}$ Giovani Bottesini, Laboratório de Sistemas de Transportes, Universidade Federal do Rio Grande do Sul, Porto Alegre, RS, Brasil. (e-mail: gbottesini@gmail.com).

${ }^{2}$ Christine Tessele Nodari, Laboratório de Sistemas de Transportes, Universidade Federal do Rio Grande do Sul, Porto Alegre, RS, Brasil. (e-mail: piti@producao.ufrgs.br).

Manuscrito recebido em 22/4/2010 e aprovado para publicação em 26/7/2011. Este artigo é parte de TRANSPORTES v.19, n.1, 2011. ISSN 2237-1346 (online).
}

em local proibido (comportamento do motorista).

No entanto, devido à grande variedade de características físicas e psicológicas das pessoas, tem-se pouco controle sobre o elemento humano (Dewar e Olson, 2007), o que dificulta seu aperfeiçoamento. Dessa forma, a identificação das medidas de segurança de trânsito que apresentam maior potencial para induzir um comportamento seguro nos motoristas pode contribuir na definição de programas de segurança com bom nível de eficiência.

Neste contexto, que destaca a importância do comportamento do motorista como fator contribuinte da ocorrência dos acidentes, este artigo objetiva identificar as principais infrações associadas à ocorrência de acidentes e as medidas de segurança capazes de coibir essas infrações. Adicionalmente, objetiva-se classificar essas medidas de segurança de trânsito de acordo com seu grau de influência em inibir o cometimento de infrações de trânsito no meio urbano. A abordagem adotada para atingir o objetivo deste estudo foi a realização de grupos focados (pesquisa qualitativa) e posterior aplicação de questionário autorrelatado (pesquisa quantitativa). Esse artigo está organizado em cinco seções: Além desta introdução, apresenta-se uma revisão teórica a respeito do tema, incluindo questões relativas ao desempenho e ao comportamento dos motoristas, bem como os fatores que os influenciam. A seguir é apresentado o método de trabalho, incluindo as etapas qualitativa e quantitativa da pesquisa. Os resultados são analisados e discutidos e, por fim, são apresentadas as principais conclusões da pesquisa.

\section{A INFLUÊNCIA DO FATOR HUMANO NOS ACIDENTES DE TRÂNSITO}

A tarefa de dirigir consiste em um ciclo compensatório de 


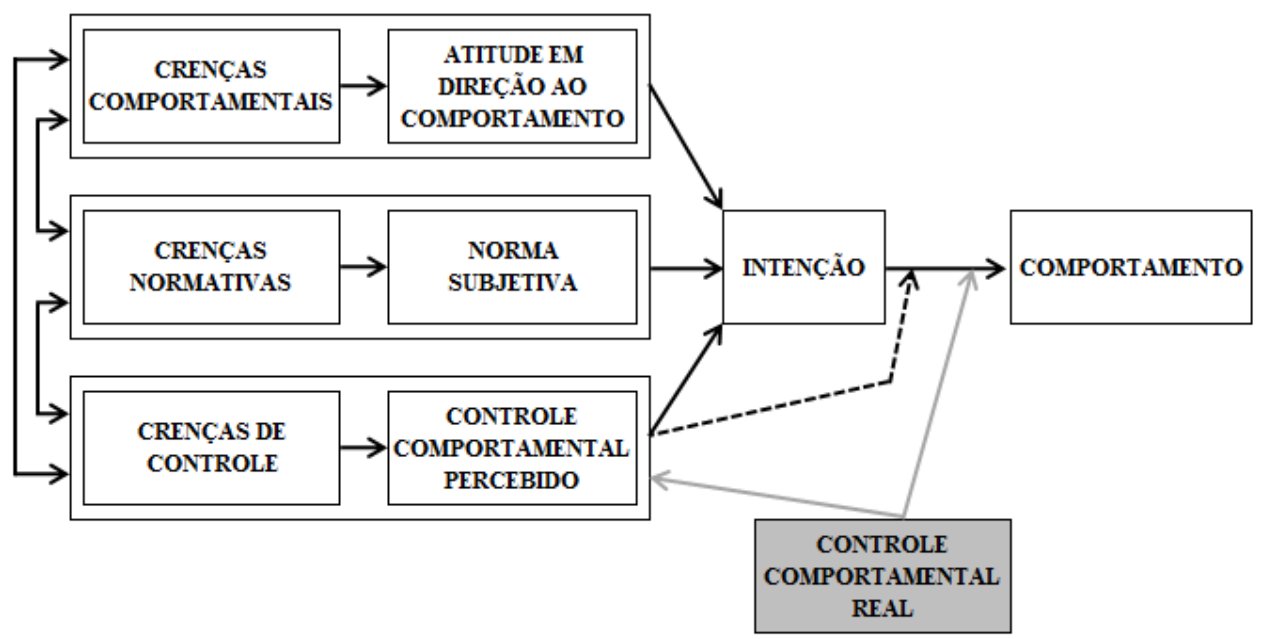

Figura 1. Teoria do comportamento planejado (adaptado de Ajzen, 2002)

feedback de ações de controle, no qual o motorista aplica uma ação de controle no veículo, monitora as consequências desta e, com base nas informações deste monitoramento, aplica uma nova ação de controle. O motorista, portanto, deve ser capaz de receber e avaliar estas respostas e decidir qual é a melhor ação a ser tomada, mantendo o sistema de tráfego, que é inerentemente instável, em equilíbrio. A ocorrência de um acidente se dá quando este equilíbrio é quebrado. Isso ocorre quando o desempenho do motorista é superado pelas demandas que o sistema de tráfego impõe sobre ele (Dewar e Olson, 2007; Shinar, 2007; Evans, 2004; Ogden, 1996).

\subsection{Desempenho e comportamento do motorista}

Existem, basicamente, duas dimensões que caracterizam o fator humano na segurança de tráfego: o desempenho e o comportamento. O desempenho do motorista pode ser traduzido como aquilo que ele é capaz de fazer, com base em suas características cognitivas e sensoriais, em seu conhecimento e em sua destreza. O comportamento, por sua vez, é aquilo que o motorista efetivamente faz ao volante, podendo ser visto como aquilo que ele escolhe fazer com suas habilidades (Evans, 2004).

Uma das teorias que mais têm obtido sucesso ao estudar o comportamento dos motoristas, especialmente envolvendo violações conscientes, direção agressiva e direção sob efeito de álcool, é a teoria do comportamento planejado, de Icek Ajzen (Shinar, 2007). De acordo com esta teoria, a ação humana é guiada por três tipos de considerações: crenças comportamentais, crenças normativas e crenças de controle. As crenças comportamentais são aquelas relativas aos possíveis resultados do comportamento e sua avaliação. Essas crenças provocam atitudes (favoráveis ou desfavoráveis) em relação ao comportamento. As crenças normativas referem-se às expectativas de terceiros e à motivação para adequar-se a essas expectativas. Resultam na norma subjetiva (ou "pressão social percebida"). Por fim, as crenças de controle são aquelas relativas à presença de fatores que possam facilitar ou impedir a execução do comportamento, e ao poder percebido desses fatores, gerando assim, o controle comportamental percebido. Essas três crenças levam à formação de uma intenção comportamental, que será mais forte quanto mais favoráveis forem a atitude e a norma subjetiva, e quanto maior for o controle percebido pelo autor sobre a ação. Por fim, dado um grau suficiente de controle real sobre o comportamento, espera-se que ele seja executado. Esse controle real, no entanto, muitas vezes é substituído pelo controle percebido, já que pode ser limitado pela dificuldade de execução de determinados comportamentos. A Figura 1 ilustra a teoria do comportamento planejado. Nesta figura, a seta tracejada representa o processo de substituição do controle comportamental real pelo controle comportamental percebido. Neste caso, o controle percebido atua tanto na formação da intenção quanto na concretização desta em um comportamento.

\subsection{Fatores que influenciam no desempenho e no comportamento}

Diversos fatores têm sido estudados quanto à sua influência no desempenho e/ou no comportamento dos motoristas, sendo que alguns pesam mais em uma ou em outra dessas dimensões do fator humano. Alguns dos principais fatores de influência são gênero, idade, experiência, treinamento e educação formais, redução temporária de capacidade, personalidade, estimativa de risco, normas sociais, mídia de massa e intervenções legislativas. Estes fatores serão abordados a seguir. A revisão sobre tais fatores está essencialmente embasada na literatura internacional, uma vez que não foram encontrados estudos nacionais relativos a esses temas.

\subsubsection{Gênero}

Em geral, os estudos revisados apontam que homens se envolvem mais frequentemente em acidentes relacionados com violações às leis de trânsito, especialmente envolvendo excesso de velocidade e embriaguez. Mulheres, por sua vez, se envolvem mais em acidentes envolvendo erros de julgamento. As mulheres também perdem o controle do veículo com mais frequência em más condições de via e de clima do que os homens. Além disso, observa-se que mulheres cometem menos infrações do que homens (Storie, 1977 apud Yagil, 1998a; Simon e Corbett, 1996 apud Yagil, 1998a; Laapotti, 2005).

Quanto à exposição, os homens dirigem com mais frequência e por maiores distâncias do que mulheres. Também dirigem mais em condições adversas e aceitam mais riscos (Nyberg e Gregersen, 2007). A avaliação das próprias habi- 
lidades é mais positiva entre os homens, enquanto as mulheres são menos confiantes neste aspecto (Tronsmoen, 2008; Laapotti, 2005). Esta maior confiança dos homens em suas habilidades pode levar a um "cumprimento seletivo das leis". O cumprimento das leis é relacionado à avaliação das mesmas, e, como mulheres percebem mais risco e "questionam" menos as leis, tendem a ter um maior senso de obrigação para cumpri-las do que os homens. Estes, por sua vez, são mais propensos a avaliar, conforme a situação, se é vantajoso ou não cumpri-las (Yagil, 1998a; Laapotti, 2005). O chamado "papel do gênero" na sociedade também tem efeitos no trânsito. O papel das mulheres é considerado passivo e não competitivo, e espera-se que não assumam riscos. Os homens, por outro lado, são encorajados a expressar raiva, assumir riscos e competir (Laapotti, 2005; Simon e Corbett, 1996 apud Ulleberg, 2001; Özkan e Lajunen, 2006). Assim, adotam a direção arriscada com mais frequência do que as mulheres. Uma revisão mais completa sobre esses fatores de influência é apresentada em Bottesini (2010).

\subsubsection{Idade}

O comportamento costuma ser determinante na ocorrência de acidentes envolvendo motoristas mais jovens, enquanto o desempenho é o fator preponderante nos acidentes com motoristas mais idosos. Motoristas jovens possuem melhores reflexos, sentidos mais aguçados e tendem a se arriscar mais. Grande parte dos acidentes sofridos por motoristas jovens é resultado de falhas provenientes de comportamentos arriscados assumidos voluntariamente, e não de falta de habilidades. Com a idade, embora a experiência e conhecimento acumulados ao longo da vida tendam a transformar as pessoas em melhores motoristas, as características físicas e motoras começam a se deteriorar. Muitos motoristas mais velhos, cientes de suas limitações, ajustam sua exposição tanto aos riscos quanto à própria atividade de dirigir, diminuindo viagens em condições perigosas ou desconfortáveis (Evans, 2004; Langford e Koppel, 2006; Blomqvist, Raitanen e O’Neill, 2002; Merat, Antilla e Luoma, 2005; Clarke, Ward e Truman, 2005).

Existe diferença também nos motivos pelos quais motoristas mais jovens e mais velhos dirigem. Os primeiros tendem a dirigir mais "por diversão". Neste sentido, dirigir em alta velocidade é considerado uma experiência agradável. Em relação as leis, os motoristas mais velhos têm um maior senso de obrigação quanto a obedecê-las, além de terem atitudes mais positivas em relação à físcalização de trânsito. Os motoristas jovens percebem as leis de trânsito como menos importantes, e também a imagem de infratores como menos negativas do que os mais velhos. (Laapotti, 2005; Falk e Montgomery, 2007; Jonah, 1986 apud Ulleberg, 2001; Yagil, 1998a; Yagil, 1998b).

\subsubsection{Experiência}

Um motorista iniciante enfrenta dificuldades em tarefas mais básicas, como a operação do veículo. Ele ainda precisa pensar no que está fazendo e no que precisa fazer, e em que ordem as tarefas devem ser executadas. Estas dificuldades costumam ser superadas rapidamente à medida que $o$ motorista repete as tarefas mais elementares, transformando-as em um processo praticamente automático. Ainda assim, o foco de atenção do motorista permanece muito próximo ao veículo. Motoristas inexperientes também utilizam os retrovisores com menor frequência, e realizam "movimentos de perseguição" com os olhos. Dessa forma, em situações de perigo, resta-lhe pouco tempo para reagir e evitar uma colisão, por exemplo. Conforme adquire mais experiência, o motorista expande seu foco de atenção até o horizonte visual, olhando rapidamente para a região mais próxima ao veículo, além de aprender a extrair uma maior quantidade de informações relevantes do ambiente de tráfego, permitindo inclusive prever situações futuras a partir delas. Essa capacidade resulta em uma diferença de $250 \mathrm{mi}-$ lissegundos no tempo de reação médio de motoristas experientes e inexperientes (Evans, 2004; Dewar e Olson, 2007; Patten et al., 2006).

A capacidade de discernir situações potencialmente perigosas é menor entre motoristas inexperientes. O resultado dessas diferenças é que as taxas de acidentes entre motoristas iniciantes são maiores nos primeiros meses de habilitação, caindo substancialmente ao longo dos dois primeiros anos dirigindo, sendo essa queda ainda mais acentuada nos seis primeiros meses. Essa redução nas taxas de acidentes ocorre em todas as idades, mas é mais acentuada entre os motoristas mais jovens, o que sugere uma interação entre idade e experiência. Apesar disso, ainda não está claro se, por exemplo, a experiência é inicialmente mais importante, dando espaço, posteriormente, a fatores relacionados à idade (Mayhew, Simpson e Pak, 2003; Borowsky, Gilad e Parmet, 2009).

\subsubsection{Treinamento e educação formais}

O treinamento e a educação inicial do condutor são necessários para que ele adquira conhecimentos a respeito da operação do veículo e das normas de circulação. No entanto, um estudo realizado por Ker et al. (2003) não encontrou evidências de que a educação para condutores já habilitados seja efetiva na redução de acidentes e de lesões, embora tenha encontrado uma pequena redução no cometimento de infrações de trânsito. Vários estudos falharam em demonstrar efeitos positivos de treinamento e educação formal (Mayhew et al., 2002; Christie, 2001). Também é pouco provável que o treinamento convencional desfaça hábitos adquiridos ao longo de anos de experiência ou altere valores e motivações de forma duradoura. Isto se aplica principalmente a países com altas taxas de motorização, pois neles as pessoas convivem desde a infância com informações, regras e formas de se comportar no trânsito.

\subsubsection{Redução temporária de capacidade}

Existem, basicamente, três tipos de condições que reduzem a capacidade dos motoristas: uso de álcool e de outras drogas, distração e desatenção, e fadiga. $\mathrm{O}$ efeito prejudicial dessas condições se manifesta majoritariamente no desempenho do motorista, mas o comportamento também pode ser afetado pelo uso de álcool e outras drogas. O álcool afeta as funções de percepção, atenção, memória e psicomotoras (Shinar, 2007). O álcool provoca, no comportamento humano, os seguintes efeitos, entre outros (GRSP, 2007): inconsistência no desempenho de tarefas comportamentais; decréscimo de julgamento e inibição; sensação de excitação, relaxamento e prazer; aumento de ansiedade e depressão; decréscimo de paciência.

Em comparação ao álcool, outras drogas não têm seu efeito na segurança de trânsito tão conhecidos, provavelmente por ser de uso menos frequente do que o álcool. De fato, 
o número de prisões efetuadas por dirigir sob efeito de outras drogas é reduzido, seja porque essa ocorrência é pouco comum (o álcool é a droga mais comumente encontrada em motoristas), seja porque a fiscalização não é capaz de identificar sua presença. Tudo isso, aliado ao fato de outras drogas serem comumente utilizadas em conjunto com o álcool, dificulta a avaliação do efeito de outras drogas isoladamente na segurança de trânsito (Shinar, 2007).

\subsubsection{Personalidade}

Diferentes indivíduos têm diferentes atitudes, capacidades intelectuais, condições físicas e psicológicas, de forma que situações idênticas originadas no trânsito podem resultar em reações opostas em dois indivíduos. Durante muito tempo, o conceito de propensão ao acidente recebeu atenção. Na literatura, alguns traços de personalidade demonstram estar ligados ao envolvimento em acidentes e à propensão ao comportamento de risco (Dewar e Olson, 2007). Ulleberg (2001) destaca, entre outros, os seguintes: busca de emoções; desvio de comportamento social; aversão a regras; hostilidade; agressividade; impulsividade; ansiedade; vulnerabilidade emocional; egoísmo. Um dos efeitos mais estudados desses traços de personalidade no trânsito é a chamada "direção agressiva" (aggressive driving). A National Highway Traffc Safety Administration (NHTSA, 2000) define direção agressiva da seguinte forma: "quando indivíduos cometem, em movimento, uma combinação de infrações de trânsito de forma a colocar em perigo outras pessoas ou propriedades".

\subsubsection{Estimativa de risco}

Embora os acidentes de trânsito ocorram em grande quantidade e as pessoas tenham consciência disto, da perspectiva do indivíduo, tratam-se de eventos raros. Por exemplo, nos Estados Unidos, a distância média viajada entre eventos, considerando acidentes fatais, é de 79 milhões de quilômetros, e o tempo médio entre eventos é de 3400 anos. Isso contribui para que se crie uma atitude otimista, uma sensação de que "nunca vai acontecer comigo" (Evans, 2004). Além da frequência de acidentes na perspectiva do indivíduo, a avaliação que o motorista faz das próprias habilidades e a experiência prévia com acidentes de trânsito, entre outros fatores, contribuem para a percepção de risco. Falk e Montgomery (2009) citam três estudos sobre os efeitos da experiência com acidentes nas atitudes e no estilo de dirigir. No primeiro deles, concluiu-se que os motoristas que tinham experiência com acidentes de trânsito eram mais cuidadosos e assumiam menos riscos se comparados a motoristas sem histórico de acidentes; no segundo estudo, a conclusão foi de que motoristas que já haviam sofrido lesões sérias (a ponto de serem hospitalizados) avaliavam suas habilidades e segurança ao dirigir de forma mais negativa do que os motoristas sem esse histórico. Além disso, também manifestavam menos intenção de exceder a velocidade no futuro; no último deles, os motoristas que atribuíram o acidente ao seu próprio comportamento relataram uma mudança duradoura no estilo de direção como efeito do acidente.

As teorias mais difundidas sobre riscos no tráfego são a teoria do risco zero, a teoria da aversão ao perigo (threat avoidance) e a teoria da homeostase do risco. Recentemente, Koornstra (2009) apresentou a teoria da adaptação ao risco, que integra as três anteriores.

\subsubsection{Normas sociais}

A influência da sociedade no comportamento dos indivíduos ocorre em razão de uma necessidade que eles, em geral, têm de obter aprovação das pessoas cujas opiniões valorizam, sendo isto particularmente forte entre os adolescentes. É comum que eles utilizem o automóvel como um meio de expressar sentimentos de independência, rebeldia, competitividade, iniciativa, entre outros. Dirigir em alta velocidade, demonstrar habilidade através de manobras arriscadas, disputar corridas e, principalmente, consumir bebidas alcoólicas são atitudes apreciadas por muitos grupos de adolescentes. Todos esses comportamentos, que parecem atender a um desejo de se exibir, demonstrar que já são adultos, ganhar a admiração dos pares, dominar o risco e superar os limites, estão inseridos na cultura, inclusive figurando em diversos filmes clássicos ou que fazem sucesso entre adolescentes, contribuindo ainda mais para que ocorram (Evans, 2004; Dewar e Olson, 2007; Bina, Graziano e Bonino, 2006). Existe também uma forte influência do comportamento dos pais sobre o dos adolescentes. Seja através de disposição genética ou de modelo de aprendizagem, os adolescentes "herdam" os hábitos de direção dos pais, sendo as correlações mais significativas encontradas entre pai e filho e entre mãe e filha (Prato et al., 2009). Outra questão relevante é a cultura em torno do automóvel. Muitas pessoas não compram automóveis simplesmente para dispor de um meio de transporte. O modelo de automóvel que uma pessoa possui pode ser traduzido como um símbolo de seu status social e econômico, além de proporcionar uma sensação de poder e superioridade sobre outras pessoas. (Evans, 2004; Dewar e Olson, 2007).

\subsubsection{Mídia de massa}

Pesquisas apontam para uma conexão causal entre a violência na mídia e comportamentos agressivos em algumas crianças (Evans, 2004; Anderson e Bushman, 2002). Johnson et al. (2002) concluíram que a exposição extensiva de adolescentes e adultos jovens à televisão associa-se à maior probabilidade de cometer atos agressivos contra outras pessoas. O mesmo se aplica à veiculação massiva do uso irresponsável do automóvel. Anúncios de automóveis, frequentemente, retratam de forma positiva o uso de veículos de maneiras sabidamente danosas, exaltando a direção irresponsável e associando-a a mensagens de poder, liberdade, diversão, aventura, emoção e status social. Ferguson et al. (2003) analisaram o conteúdo de mais de 500 comerciais de automóveis veiculados no ano de 1998 nos Estados Unidos, na Europa e na Ásia. O desempenho do veículo foi o tema que mais apareceu como principal (em 17\% dos comerciais), tendo sido mencionado em cerca de 50\% dos comerciais analisados. Em seguida, aparecem os temas incentivos/vendas, economia, novidade, qualidade/confiabilidade/durabilidade. A segurança apareceu como tema principal em apenas $2 \%$ dos anúncios, sendo mencionado em $8 \%$, embora estudos tenham demonstrado que segurança tem um papel importante na decisão de compra de um carro. No Reino Unido, uma comissão independente rejeita a velocidade como tema publicitário. Segundo essa comissão, "velocidade não é uma plataforma aceitável para a publicidade de automóveis". Neste país, os comerciais não podem apresentar a condução de veículos em alta velocidade como excitante ou prazerosa, nem retratá-la como um esporte competitivo. Também não pode haver a sugestão de que dirigir 
com segurança ou cautela seja tedioso (Ferguson et al., 2003).

\subsubsection{Intervenções legislativas}

As leis contribuem para a segurança de trânsito determinando como os motoristas devem se comportar. Essa determinação é feita com base em estudos cujas conclusões apontam que determinados comportamentos são mais seguros do que outros. No entanto, uma lei sancionada, por si só, irá modificar apenas o comportamento daqueles motoristas que acreditam que obedecer às leis é um princípio de cidadania. Os demais motoristas modificarão seu comportamento simplesmente a fim de evitar as penalidades previstas na legislação. Para estes casos, o nível de obediência à lei depende da percepção que as pessoas têm sobre o quão fortemente ela está sendo fiscalizada. Também influenciam o comportamento dos motoristas o valor da multa ou a possibilidade de receber uma penalização mais severa, como suspensão do direito de dirigir ou prisão. (Evans, 2004; Ferraz et al., 2008).

O cumprimento de uma nova lei costuma ser elevado imediatamente após a sua entrada em vigor. Após certo período de tempo, os níveis de obediência decaem à medida que os motoristas percebem que a detecção de infrações é pouco provável (Evans, 2004). Redelmeier et al. (2003) estudaram motoristas que já haviam se envolvido em acidentes com mortes, a fim de analisar o efeito de punições recentes em motoristas, individualmente. Os autores encontraram uma redução de $35 \%$ no risco de um acidente fatal no primeiro mês após uma condenação. No Brasil, observou-se um fenômeno semelhante com a entrada em vigor do novo Código de Trânsito Brasileiro (Brasil, 1997). De acordo com Viana (2005) e Kume (2007), o novo Código de Trânsito Brasileiro teve um efeito passageiro em relação à redução das taxas de acidentes, durando três ou quatro anos.

\subsection{Medidas de segurança de trânsito voltadas ao fator humano}

A legislação de trânsito, que tem por objetivo tornar o comportamento o mais previsível e seguro possível, é uma importante medida de segurança de trânsito. Buscando assegurar seu êxito, são utilizadas as medidas de fiscalização e as sanções legais. Além dessas, são utilizadas medidas de educação e informação ao público, em especial as campanhas de conscientização na mídia (Elvik e Vaa, 2004; Ferraz et al., 2008).

A legislação de trânsito brasileira (Brasil, 1997) prevê as seguintes penalidades: advertência por escrito; multa; suspensão e cassação do direito de dirigir; frequência obrigatória em curso de reciclagem e apreensão do veículo. Além dessas penalidades, de natureza administrativa, são previstas penas de detenção para os crimes de trânsito (dirigir sob o efeito de álcool ou outras substâncias, lesão corporal, homicídio, etc.). Todas essas sanções buscam desencorajar o cometimento de infrações de trânsito, através da ameaça de punição percebida pelos motoristas (Elvik e Vaa, 2004). Também é comum que se ofereçam incentivos aos motoristas que não se envolvem em acidentes e/ou que não recebem multas de trânsito. No Brasil, alguns governos estaduais concedem descontos no valor do IPVA para veículos que não tenham sido multados durante certo período. No Estado do Rio Grande do Sul, o valor deste desconto chega a $15 \%$ se não houver multas durante dois anos (Elvik e Va- a, 2004; Rio Grande do Sul, 2001).

De acordo com Elvik e Vaa (2004), mesmo que o risco real de ser flagrado seja muito baixo, a simples possibilidade de, por exemplo, a velocidade estar sendo verificada influencia o comportamento dos motoristas. Em geral, do ponto de vista de um motorista, o risco de ser flagrado cometendo uma infração é muito pequeno. A fiscalização eletrônica automática é utilizada para aumentar a capacidade de fiscalização de forma a não exigir a presença de policiais ou agentes de trânsito no local da infração. Dessa forma, o risco percebido pelo motorista de ser flagrado será elevado em alguns locais específicos (Elvik e Vaa, 2004).

As campanhas de conscientização visam reduzir acidentes promovendo um comportamento seguro no trânsito, dando, principalmente aos motoristas, melhores conhecimentos e promovendo atitudes favoráveis a tal comportamento. Outro objetivo é esclarecer as restrições impostas, para que haja maior entendimento sobre o motivo da sua existência. Quanto à efetividade, as campanhas de conscientização apresentam resultados diversos. Campanhas voltadas a acidentes em geral, ou seja, sem um foco específico, não demonstram mudanças significativas no número de acidentes. No entanto, melhores resultados parecem ser atingidos quando: $i$ ) as campanhas mostram claramente que tipo de mudança comportamental é desejada, e porque esta mudança é importante; ii) as campanhas são veiculadas na televisão, uma mídia que alcança um público mais amplo; iii) as campanhas são combinadas a um aumento na fiscalização; e $i v$ ) a proporção inicial de usuários apresentando o comportamento desejado é pequena (Elvik e Vaa, 2004; Ferraz, Raia Jr. e Bezerra, 2008).

\section{MÉTODO DE ESTIMATIVA DA INFLUÊNCIA DE MEDIDAS DE SEGURANÇA}

O método delineado para se atingir o objetivo deste trabalho consistiu no desenvolvimento consecutivo de duas pesquisas, uma qualitativa e uma quantitativa. A pesquisa qualitativa foi realizada por meio de Grupos Focados, nos quais buscou-se levantar subsídios para a elaboração da pesquisa quantitativa. A pesquisa quantitativa, por sua vez, consistiu na aplicação de um questionário a motoristas de automóvel da cidade de Porto Alegre/RS. Neste questionário, buscou-se identificar quais medidas de segurança de trânsito se mostram mais influentes no comportamento dos motoristas. As respostas, na forma de uma escala numérica, foram analisadas, posteriormente, calculando-se um escore para cada medida de segurança e ordenando-as de forma decrescente. Esse escore foi denominado "potencial de influência" de uma medida de segurança no comportamento dos motoristas.

\subsection{Pesquisa Qualitativa}

A etapa qualitativa deste estudo consistiu na condução de dois Grupos Focados a respeito do tema "o fator humano nos acidentes de trânsito". Ambos foram conduzidos de forma similar, sendo a principal diferença entre eles o contexto: no primeiro, o tema "o fator humano nos acidentes de trânsito" foi abordado considerando-se o ambiente rodoviário. No segundo, o mesmo tema foi discutido considerando o ambiente urbano. Foram selecionadas para participar dos Grupos Focados diversas pessoas envolvidas com o tema, incluindo motoristas de automóvel, de ônibus, de cami- 


\begin{tabular}{|c|c|c|c|c|c|c|c|}
\hline \multicolumn{8}{|c|}{$\begin{array}{l}\text { Quanto cada medida listada influi ou influiria na sua decisão de não exceder o limite de velocidade? } \\
\text { Legenda: } 1 \text { = nada; } 4 \text { = mais ou menos; } 7=\text { totalmente }\end{array}$} \\
\hline Presença de fiscais de trânsito/policiais (ostensivos, visiveis) & 1 & 2 & 3 & 4 & 5 & 6 & 7 \\
\hline Radar móvel sem avisos de sua presença & 1 & 2 & 3 & 4 & 5 & 6 & 7 \\
\hline Perder o direito de dirigir (suspensão/cassação da carteira) & 1 & 2 & 3 & 4 & 5 & 6 & 7 \\
\hline
\end{tabular}

Figura 2. Exemplo de questões da pesquisa quantitativa

nhão, motociclistas, ciclistas, pedestres, taxistas, agentes de fiscalização, gestores e especialistas no assunto. Os participantes foram estimulados a expor sua visão sobre: $i$ ) quais são as principais infrações que contribuem para que ocorram acidentes de trânsito; ii) que motivos levam os motoristas a cometerem essas infrações, e; iii) o que poderia fazer os motoristas deixarem de cometer essas infrações.

Como resultado da pesquisa qualitativa, tem-se que, na opinião dos participantes, as infrações que mais contribuem para acidentes de trânsito em rodovias são as ultrapassagens indevidas, o excesso de velocidade, a embriaguez e o desrespeito à distância segura de seguimento. No meio urbano, o excesso de velocidade, o avanço de sinal vermelho de semáforo e a realização de manobras sem a devida sinalização foram consideradas as principais infrações que contribuem para acidentes. Foram relatados diversos motivos pelos quais os motoristas cometem, intencionalmente, essas infrações. Entre os principais, podem ser citados os seguintes: pressa; individualismo; percepção do carro como extensão da residência; excesso de confiança nas habilidades; excesso de confiança no veículo; sensação de anonimato na direção; sensação de impunidade; cultura de poder e superioridade em torno do automóvel; subestimação dos riscos em função da capacidade do veículo e das boas condições de algumas vias; etc. Quanto às medidas para inibir o cometimento das infrações citadas, os participantes mencionaram as seguintes, entre outras: campanhas de conscientização; qualificação da formação dos condutores; policiamento ostensivo; fiscalização eletrônica; garantia de punição; multas mais caras; limites de velocidade variáveis em função do fluxo de veículos; semáforos com temporizador; dispositivos de segurança no veículo; registrador de velocidade nos veículos, etc. As informações levantadas na pesquisa qualitativa, combinadas à revisão da literatura, serviram como base para a elaboração do instrumento da pesquisa quantitativa.

\subsection{Pesquisa quantitativa}

A pesquisa quantitativa conduzida neste estudo foi realizada na forma de um questionário, que foi aplicado a motoristas de automóvel da cidade de Porto Alegre. Na primeira parte do questionário, foram incluídas diversas variáveis que servem para traçar um perfil da amostra pesquisada. As variáveis incluídas na primeira parte do questionário estão, direta ou indiretamente, relacionadas aos fatores de influência do comportamento identificadas na revisão teórica: sexo, idade, estado civil, se tem filhos ou não, renda mensal pessoal, escolaridade, tempo de habilitação na categoria $\mathrm{B}$ (automóvel), se dirige profissionalmente ou não, qual modelo de automóvel costuma dirigir, se é o proprietário deste veículo, com que frequência dirige, principal motivo dos deslocamentos de automóvel, se já se envolveu em acidentes (e em que tipos), se já foi multado nas infrações pesquisadas e com que frequência comete essas infrações, inde- pendente de receber multa.

A segunda parte do questionário contém questões a respeito de diversas medidas de segurança de trânsito. O respondente é solicitado a informar em que nível cada uma delas influencia os motoristas a não praticar as infrações consideradas mais importantes pelos participantes da pesquisa qualitativa. De acordo com Ajzen (2002), autor da teoria do comportamento planejado, para estudar um determinado comportamento, existem duas opções: a observação e o autorrelato. A observação fornece uma medida mais confiável, mas sua execução é muito difícil, já que exigiria que um observador registrasse um determinado comportamento sempre que ele fosse executado pelos participantes do estudo e sob determinadas condições. Já o autorrelato, embora nem sempre tenha validade assegurada, é mais facilmente obtido. Os participantes de um estudo envolvendo autorrelato respondem as questões através do uso de escalas de diferencial semântico.

As escalas de diferencial semântico são um instrumento onde determinado objeto (produto, organização, pessoa, fato ou situação) é avaliado por meio de escalas bipolares de sete pontos, podendo ser atribuído um valor numérico para cada um deles. Algumas das qualificações bipolares mais comuns são bom/mau, valioso/sem valor, forte/fraco, rápido/lento. No entanto, existe grande liberdade para empregar qualificações diferentes (Mattar, 2005). Neste estudo, foi utilizado o seguinte formato de questões: uma pergunta genérica para cada infração, seguida de uma lista de medidas de segurança, cada uma recebendo uma resposta. A Figura 2 exemplifica as questões utilizadas, tal como foram apresentadas no questionário.

O questionário, em seu formato final, foi composto de 15 questões de caracterização do respondente e 61 questões referentes às infrações estudadas: uso de álcool ao dirigir, excesso de velocidade e avanço de sinal vermelho de semáforo. As 61 questões dividem-se em 3 grupos, sendo cada um deles relativo a uma das três infrações estudadas. Cada uma dessas 61 questões corresponde a uma medida de segurança de trânsito, sendo algumas dessas medidas de abrangência geral (aplicáveis a qualquer infração de trânsito), de forma que se repetem nos três grupos de questões. Outras medidas são de abrangência específica a uma determinada infração, por isso constam apenas em um grupo de questões. A relação completa dos aspectos abordados nas questões apresentadas no questionário é apresentada a seguir:

- Questões com medidas de segurança relativas às três infrações estudadas: Campanha de conscientização em rádio, TV ou jornal com imagens fortes, mutilações, etc.; Campanha de conscientização em rádio, TV ou jornal com conteúdo emotivo; Campanha de conscientização em rádio, TV ou jornal com conteúdo técnico (informativo); Campanha de conscientização em rádio, TV ou jornal com celebridades 
Tabela 1. Conversão da escala de diferencial semântico para uma escala de probabilidades

\begin{tabular}{lccccccc}
\hline Escala de respostas & $\mathbf{1}$ & $\mathbf{2}$ & $\mathbf{3}$ & $\mathbf{4}$ & $\mathbf{5}$ & $\mathbf{6}$ & $\mathbf{7}$ \\
\hline Escala de probabilidades & $5 \%$ & $20 \%$ & $35 \%$ & $50 \%$ & $65 \%$ & $80 \%$ & $95 \%$ \\
Pesos & 5 & 20 & 35 & 50 & 65 & 80 & 95 \\
\hline
\end{tabular}

(pessoas famosas); Amigo(a) chamando a atenção; Namorado(a)/esposo(a) chamando a atenção; Pai ou mãe chamando a atenção; Filho(s) chamando a atenção; Presença de fiscais de trânsito/policiais (ostensivos, visíveis); Saber que podem existir fiscais de trânsito/policiais à paisana (disfarçados, sem uniforme); Valor da multa proporcional à renda pessoal; Valor da multa proporcional ao valor do veículo; Perder o desconto no IPVA se for multado; Perder o direito de dirigir (suspensão/cassação da carteira); Seguro do veículo ficar mais caro se for multado nesta infração;

- Questões com medidas de segurança relativas ao consumo de bebidas alcoólicas: Blitz com bafômetro; Obrigatoriedade de fazer o teste do bafômetro quando solicitado; Seguro do veículo ficar mais caro se for multado nesta infração; Possibilidade de ser preso; Possibilidade de ter o veículo apreendido se for multado nesta infração;

- Questões com medidas de segurança relativas ao excesso de velocidade: A sinalização explicar o motivo do limite de velocidade (escola, travessia de pedestres, etc.); Andar acima do limite causa sensação de insegurança (em função do projeto das ruas); Pardais sinalizados (localização conhecida) - influência no trecho próximo ao pardal; Pardais sinalizados (localização conhecida) - influência no restante do trecho; Pardais não sinalizados (localização desconhecida) - influência no trecho inteiro; Radar móvel sem avisos de sua presença; Registrador de velocidade no veículo (tacógrafo); Possibilidade de ter o veículo apreendido se for multado várias vezes; e

- Questões com medidas de segurança relativas ao avanço de sinal vermelho de semáforo: Fiscalização eletrônica, que fotografa os veículos que passam no vermelho (Caetanos); Segurança pública (perceber que não há risco de assalto); Temporizador (mostra quanto tempo de verde/vermelho resta); Possibilidade de ter o veículo apreendido se for multado várias vezes.

O questionário foi aplicado aos motoristas de automóvel que dirigem na cidade de Porto Alegre. A amostra foi estratificada em função do gênero (masculino e feminino) e da idade (18 a 25 anos, 26 a 35, 36 a 45, 46 a 60 e mais de 60 anos) dos respondentes, resultando em 10 estratos. A razão da estratificação ser feita em função de gênero e idade reside na constatação, conforme o referencial teórico, de que a maior parte dos fatores de influência do comportamento dos motoristas está associada, de alguma forma, com gênero e/ou idade. Exemplificando: a experiência tende a ser maior quanto mais velho for o motorista, e homens dirigem maiores distâncias do que mulheres; mulheres recebem uma proporção maior de instrução profissional (treinamento e educação formal); homens dirigem mais sob influência de substâncias (redução temporária de capacidade); homens e motoristas jovens aceitam mais riscos; jovens são mais in- fluenciados pelas normas sociais, além de existirem os chamados "papéis do gênero" (gender roles) na sociedade; as atitudes em relação às leis de trânsito (intervenções legislativas) diferem entre homens e mulheres e entre motoristas mais jovens e mais velhos.

Com um nível de significância de $95 \%$, um coeficiente de variação em torno de $10 \%$ e um erro relativo admissível de $7 \%$, a quantidade de questionários em cada estrato resultou igual a 8, o que corresponde a uma amostra total de 80 questionários. Como deseja-se a mesma precisão na análise, independente do tamanho das subpopulações de cada estrato, foram utilizadas amostras de mesmo tamanho para todos os estratos (Ribeiro e Echeveste, 1998).

\subsection{Cálculo do potencial de influência das medidas de segurança estudadas}

As respostas obtidas nos questionários foram transformadas em um escore numérico, denominado "potencial de influência", que foi calculado para cada uma das medidas de segurança presentes no questionário. Para transformar as resposta em um escore numérico, a cada opção de resposta foi associado um peso, com base em uma escala de probabilidades, que representa a influência de uma determinada medida de segurança sobre um determinado indivíduo. Na escala de diferencial semântico usada, "nada" significa que a medida influencia o motorista em 5\%, e que "totalmente" influencia em 95\%. Estes valores foram utilizados considerando que os entrevistados podem, em algum momento, comportar-se de forma diferente de sua resposta. Ou seja, eventualmente, uma medida de segurança considerada totalmente influente por um motorista não terá efeito sobre o seu comportamento, e vice-versa para uma medida considerada sem influência. Ainda, assume-se que os respondentes interpretam essa escala de forma linear (ou seja, que a diferença entre cada duas opções de resposta consecutivas é constante). A Tabela 1 apresenta a relação entre a escala de repostas e os pesos adotados.

É importante destacar que este trabalho não tem a pretensão de determinar valores de eficiência das medidas de segurança. Se o potencial de influência calculado para uma medida de segurança resultar em 90, por exemplo, isto não significa que, se esta medida for implantada, $90 \%$ dos motoristas deixarão de cometer uma determinada infração. $\mathrm{O}$ significado deste valor é que, quanto mais alto ele for, maior é a predisposição do motorista a não cometê-la, influenciado pela medida de segurança em questão. Usando os pesos da Tabela 1, foi calculado o potencial de influência da medida de segurança para cada estrato $\left(\mathrm{P}_{\mathrm{E}}\right)$ e o Potencial de influência geral da medida de segurança $\left(\mathrm{P}_{\mathrm{M}}\right)$. A equação apresenta a fórmula do cálculo do $\mathrm{P}_{\mathrm{E}}$ :

$$
P_{E}=\frac{5 n_{1}+20 n_{2}+35 n_{3}+50 n_{4}+65 n_{5}+80 n_{6}+95 n_{7}}{n_{1}+n_{2}+n_{3}+n_{4}+n_{5}+n_{6}+n_{7}}
$$

em que,

$P_{E}$ : potencial de influência da medida de segurança em um determinado estrato; e 
$n_{1, \ldots, 7}:$ quantidade de respostas nas opções 1 a 7 , respectivamente.

A Equação 2 permite que seja calculado o Potencial de influência geral da medida de segurança, considerando a participação de cada estrato da pesquisa na população de condutores habilitados:

$$
P_{M}=\frac{\sum_{E=1}^{10} P_{E} \cdot H_{E}}{\sum_{E=1}^{10} H_{E}}
$$

em que,

$P_{M}$ : Potencial de influência geral da medida de segurança;

$P_{E}$ : Potencial de influência da medida de segurança em cada um dos 10 estratos; e

$H_{E}$ : Número de habilitações registradas em Porto Alegre, em cada um dos 10 estratos.

As medidas de segurança foram, então, classificadas em ordem decrescente de potencial de influência, para cada infração de trânsito.

\section{RESULTADOS E DISCUSSÃO}

No total, foram respondidos 105 questionários, sendo 80 válidos e 25 descartados. Os questionários descartados foram aqueles que retornaram incompletos ou que apresentavam indícios de que os respondentes não haviam compreendido seu conteúdo. Os 80 questionários válidos dividiram-se igualmente entre as variáveis de estratificação (gênero e idade), com 8 questionários para cada estrato. Em relação ao estado civil, $51 \%$ dos respondentes são casados e $39 \%$ são solteiros, sendo $10 \%$ separados, divorciados ou viúvos. Pouco mais da metade dos respondentes, 55\%, têm filhos. Quanto à renda, 33\% ganham entre 5 e 10 salários mínimos, $28 \%$ ganham entre 2 e 5 salários mínimos e $23 \%$ ganham entre 10 e 20 salários mínimos. Do total, $17 \%$ ganham menos de 2 ou mais de 20 salários mínimos. Uma parcela de $15 \%$ dos respondentes possui no máximo ensino médio completo. Em relação ao tempo de habilitação na categoria B (a que permite a condução de automóveis), 59\% a obtiveram antes de 1998, ano em que o novo código de trânsito brasileiro entrou em vigor. $41 \%$, portanto, foram habilitados segundo os procedimentos implementados por este novo código. 5\% dos respondentes dirigem profissionalmente. Quanto à frequência de condução de veículo, $64 \%$ dirigem 4 ou mais vezes por semana dentro de Porto Alegre. $44 \%$ relatam nunca terem se envolvido em qualquer acidente de trânsito. Duas, das 80 pessoas entrevistadas de forma válida, já se envolveram em acidentes com feridos ou mortos, sendo ambas mulheres na faixa dos 36 aos 45 anos de idade. Nenhum dos respondentes relata já ter sido multado por dirigir embriagado, embora $9 \%$ deles afirmem dirigir após consumir álcool com certa frequência ("frequentemente" ou "às vezes"). $43 \%$ já foram multados por excesso de velocidade, mesmo percentual dos que afirmam cometer esta infração com alguma frequência. 15\% avançam sinal vermelho de semáforo com certa frequência, e $10 \%$ já foram multados por isso.

Após a obtenção de todos questionários válidos necessários, as respostas foram tabuladas de forma a permitir a análise das informações coletadas. Os dados foram organi- zados de acordo com a estratificação da amostra (por gênero e faixa etária). Em seguida, calculou-se o potencial de influência específico de cada estrato para cada uma das medidas de segurança, através da Equação 1, apresentada na seção 3.3. Como exemplo, a Tabela 2 e a Equação 3 apresentam o cálculo de $P_{F 36-45}$, que é o potencial de influência da medida de segurança "radar móvel não sinalizado", voltada à infração "excesso de velocidade", para o estrato "feminino - 36 a 45 anos".

Tabela 2. Distribuição de respostas para uma medida de segurança

\begin{tabular}{lrrrrrrr}
\hline $\begin{array}{l}\text { Medida: Radar móvel não sinalizado } \\
\text { Estrato: Feminino, 36 a } \\
\text { 45 anos }\end{array}$ \\
\hline Resposta & 1 & 2 & 3 & 4 & 5 & 6 & 7 \\
Peso & 5 & 20 & 35 & 50 & 65 & 80 & 95 \\
Quantidade & 1 & 0 & 0 & 1 & 1 & 3 & 2 \\
\hline
\end{tabular}

$P_{F 36-45}=\frac{5 \cdot 1+20 \cdot 0+35 \cdot 0+50 \cdot 1+65 \cdot 1+8 \cdot 3+95 \cdot 2}{1+0+0+1+1+3+2}$

$\mathrm{O}$ mesmo procedimento foi realizado para os demais estratos. Em seguida, calculou-se $\mathrm{P}_{\mathrm{RM}}$ por meio da Equação 2. O $P_{R M}$ representa o potencial de influência da medida de segurança "Radar móvel não sinalizado". A Tabela 3 e a Equação 4 apresentam o cálculo completo do $P_{R M}$.

Tabela 3. Cálculo do potencial de influência para uma medida de segurança

\begin{tabular}{|c|c|c|c|}
\hline Estrato & $\begin{array}{l}\text { Potencial de } \\
\text { Influência } \\
\left(P_{E}\right)\end{array}$ & $\begin{array}{l}\text { Habilitações } \\
\left(H_{E}\right)\end{array}$ & $P_{E} \cdot H_{E}$ \\
\hline $\begin{array}{l}\text { Masculino } \\
18-25 \text { anos }\end{array}$ & 83,75 & 42640 & 3571100,0 \\
\hline $\begin{array}{l}\text { Feminino } \\
18-25 \text { anos }\end{array}$ & 76,25 & 21454 & 1635867,5 \\
\hline $\begin{array}{l}\text { Masculino } \\
26-35 \text { anos }\end{array}$ & 74,38 & 86400 & 6426000,0 \\
\hline $\begin{array}{l}\text { Feminino } \\
26-35 \text { anos }\end{array}$ & 89,38 & 53468 & 4778702,5 \\
\hline $\begin{array}{l}\text { Masculino } \\
36-45 \text { anos }\end{array}$ & 85,63 & 73239 & 6271089,4 \\
\hline $\begin{array}{l}\text { Feminino } \\
36-45 \text { anos }\end{array}$ & 68,75 & 45578 & 3133487,5 \\
\hline $\begin{array}{l}\text { Masculino } \\
46-60 \text { anos }\end{array}$ & 78,13 & 105166 & 8216093,8 \\
\hline $\begin{array}{l}\text { Feminino } \\
46-60 \text { anos }\end{array}$ & 85,63 & 64190 & 5496268,8 \\
\hline $\begin{array}{l}\text { Masculino } \\
+60 \text { anos }\end{array}$ & 63,13 & 80120 & 5057575,0 \\
\hline $\begin{array}{l}\text { Feminino } \\
+60 \text { anos }\end{array}$ & 87,50 & 32934 & 2881725,0 \\
\hline & $\Sigma$ & 605189 & 47467909,4 \\
\hline
\end{tabular}

$$
P_{R M}=\frac{\sum_{E=1}^{10} P_{E} \cdot H_{E}}{\sum_{E=1}^{10} H_{E}}=\frac{47467909,4}{605189}=78,43
$$

O número de habilitações registradas em Porto Alegre, para cada estrato $\left(H_{E}\right)$, foi fornecido pelo DETRAN do Rio Grande do Sul, e é apresentado na Tabela 4.

Após calculado o potencial de influência de cada medida, elas foram ordenadas de forma decrescente. Para a em- 
Tabela 4. Condutores habilitados na categoria B em Porto Alegre

\begin{tabular}{lcc}
\hline Idade & Masculino & Feminino \\
\hline $18-25$ & 42640 & 21454 \\
$26-35$ & 86400 & 53648 \\
$36-45$ & 73239 & 45578 \\
$46-60$ & 105166 & 64190 \\
+60 & 80120 & 32934 \\
\hline
\end{tabular}

briaguez, as cinco medidas de segurança que apresentaram maior potencial de influência foram as seguintes (entre parênteses, respectivo valor de potencial de influência): possibilidade de ser preso $(90,3)$; perda do direito de dirigir $(88,9)$; apreensão do veículo $(86,3)$; fiscalização ostensiva $(85,5)$ e blitz com bafômetro $(83,3)$. A infração excesso de velocidade teve, como medidas mais influentes: perda do direito de dirigir $(87,5)$; pardais sinalizados - no trecho próximo ao equipamento $(86,2)$; fiscalização ostensiva $(85,3)$; apreensão do veículo $(84,0)$ e fillhos chamando a atenção $(81,4)$. Para o avanço de sinal vermelho, as medidas mais influentes foram: fiscalização eletrônica $(91,1)$; perda do direito de dirigir $(86,1)$; apreensão do veículo $(84,3)$; fiscalização ostensiva $(82,7)$ e segurança pública $(81,1)$. Nota-se que, via de regra, as medidas de segurança que apresentaram os maiores valores de potencial de influência são aquelas relacionadas à restrição de direitos do motorista ou à possibilidade de ele ser flagrado cometendo infrações.

As campanhas de conscientização, por outro lado, sempre figuraram entre as medidas com menor potencial de influência no comportamento dos motoristas. Dentro deste grupo de medidas de segurança, as campanhas com conteúdo chocante, isto é, exibindo cenas explícitas de acidentes, ferimentos, mutilações, entre outras, aparecem sempre com o maior valor de potencial de influência $(66,1 / 65,3 / 61,7)$. Os três valores apresentados entre parênteses referem-se ao potencial de influência das medidas de segurança sobre as infrações "embriaguez ao volante", "excesso de velocidade" e "avanço de sinal vermelho de semáforo", respectivamente. As campanhas que utilizam pessoas famosas para passar sua mensagem sempre apresentaram o menor valor de potencial de influência, não só entre as medidas de segurança desta natureza, mas entre todas as pesquisadas $(36,0 / 39,4 / 41,8)$.

Nas posições intermediárias, aparecem medidas que oferecem vantagens ou desvantagens financeiras, havendo consistência na ordem relativa entre elas: "valor da multa proporcional à renda pessoal" apresentou, dentro deste grupo de medidas, o potencial de influência mais elevado nas três infrações $(77,2 / 79,6 / 78,8)$. O potencial de influência mais reduzido, também nas três infrações, foi "perder o desconto no IPVA" (66,2/72,2/73,3). As medidas de segurança "valor da multa proporcional ao valor do veículo" e "seguro do veículo ficar mais caro" alternaram-se no segundo e no terceiro lugares. Algo similar ocorre com medidas do tipo "pessoas chamando a atenção do motorista". Dentro deste grupo de medidas e nas três infrações, o maior valor de potencial de influência sempre ocorre quando se trata de filhos chamando a atenção dos pais $(81,4 / 81,4 / 74,7)$. Quando se trata de amigos chamando a atenção do motorista, o potencial de influência sempre se apresenta com o menor valor dentro deste grupo de medidas $(63,8 / 62,4 / 62,6)$, e as posições intermediárias se alternam entre pai/mãe e namorado(a)/esposo(a).
Adicionalmente, verificou-se, por meio da análise de variância, se e quais variáveis apresentam indícios de interferirem no potencial de influência das medidas de segurança. No entanto, ao analisar as informações que seguem, é preciso ter cautela, já que, com exceção das variáveis gênero e idade, a amostragem não foi dimensionada com rigor estatístico. As campanhas de conscientização foram as medidas que apresentaram indícios de diferença significativa para o maior número de variáveis. As demais medidas, quando indicavam possíveis diferenças, o faziam de forma mais pontual, para poucas variáveis. De forma geral, com poucas exceções, as medidas de segurança parecem ter mais influência:

- em mulheres do que em homens;

- em pessoas mais velhas do que em pessoas mais jovens;

- em pessoas casadas do que em pessoas solteiras;

- em pessoas com filhos do que em pessoas sem filhos;

- em pessoas com menor escolaridade do que em pessoas com maior escolaridade;

- em pessoas habilitadas durante a vigência do antigo código de trânsito do que em pessoas habilitadas sob a vigência do novo código de trânsito;

- em motoristas profissionais do que em motoristas não profissionais;

- em pessoas que nunca foram multadas do que em pessoas que já foram multadas; e

- em pessoas que relatam cometer infrações com certa frequência do que em pessoas que relatam não cometê-las.

As únicas variáveis que não apresentaram indícios de interferir significativamente na influência de nenhuma das medidas de segurança foram renda e envolvimento em acidentes.

\section{CONCLUSÕES}

Entre os elementos que compõem o sistema de tráfego, o elemento humano é o que contribui mais fortemente para a ocorrência de acidentes, principalmente através do comportamento. Neste artigo, buscou-se identificar as medidas de segurança de trânsito que mais influenciam os motoristas a não cometerem infrações. Para tanto, foram conduzidas uma pesquisa qualitativa e uma quantitativa. Na pesquisa qualitativa, identificaram-se as principais infrações que provocam acidentes de trânsito no meio urbano: embriaguez, excesso de velocidade e avanço de sinal vermelho de semáforo. Além disso, foram levantados subsídios para elaborar um questionário, correspondente à pesquisa quantitativa. Esta, por sua vez, foi aplicada junto a motoristas de automóvel da cidade de Porto Alegre. Eles foram solicitados a declararem o quanto determinadas medidas de segurança os influencia a não cometerem as infrações de trânsito citadas acima.

A principal conclusão evidenciada pelos resultados da pesquisa indica que as medidas de segurança que mais influenciam os motoristas a não cometerem infrações de trânsito são aquelas relacionadas à restrição de direitos como forma de punição e à probabilidade de ser flagrado cometendo infrações (o que conduziria às punições). Por outro lado, as campanhas de conscientização na mídia foram as 
medidas que demonstraram ter menor influência no comportamento dos motoristas. No entanto, o fato de as campanhas de conscientização terem demonstrado sempre o menor potencial de influência no comportamento dos motoristas não significa que elas não sejam importantes e que devam ser abandonadas. As medidas de segurança devem ser aplicadas em conjunto. Mesmo que a fiscalização e a aplicação das sanções previstas em leis venham a ser priorizadas na busca pela redução dos acidentes de trânsito, devido ao seu maior potencial de influência, é importante que a população seja constantemente exposta ao tema e lembrada de sua importância. Assim, a longo prazo, talvez seja possível criar uma cultura de segurança baseada não apenas no medo de receber punições, mas no conhecimento e no exercício consciente da cidadania. Isso também possibilitaria a redução de custos da segurança de trânsito, já que fiscalizar de forma ampla e intensa exige grande quantidade de recursos.

\section{AGRADECIMENTOS}

Os autores agradecem ao $\mathrm{CNPq}$ pelo apoio financeiro concedido para a realização da pesquisa.

\section{REFERÊNCIAS BIBLIOGRÁFICAS}

Ajzen, I. (2002) Constructing a TpB questionnaire: conceptual and methodological considerations. Disponível em: $<$ http://www.people. umass.edu/aizen/pdf/tpb.measurement.pdf $>$.(Acessado em $15 / 5 / 2008)$

Anderson, C.A. e B. J. Bushman (2002) The effects of media violence on society. Science, n. 295, p. 2377-2378.

Blomqvist, L.H.; T. Raitanen e D. O'Neill (2002) Driver ageing does not cause higher accident rates per $\mathrm{km}$. Transportation Research Part F. v. 5, n. 4, p. 271-274.

Borowsky, A.; T. O. Gilad e Y. Parmet (2009) Age and skill differences in classifying hazardous traffic scenes. Transportation Research Part F. v. 12, n. 4, p. 277-287.

Bottesini, G. (2010) Influência de medidas de segurança de trânsito no comportamento dos motoristas. Dissertação (mestrado). Programa de Pós-Graduação em Engenharia de Produção, Escola de Engenharia, Universidade Federal do Rio Grande do Sul. Porto Alegre.

Brasil (1997) Código de trânsito brasileiro. Lei 9.503, de 23 de setembro de 1997. Publicada no Diário Oficial da União em 24 de setembro de 1997.

Christie, R. (2001) The effectiveness of driver training as a road safety measure: a review of the literature. Royal Automobile Club of Victoria, n. 01/03. Noble Park, Australia.

Clarke, D.D.; P. Ward e W. Truman (2005) Voluntary risk taking and skill deficits in young driver accidents in the UK. Accident Analysis and Prevention, v. 37, n. 3, p. 523-529.

Dewar, R. e P. Olson (2007) Human Factors in Traffic Safety (2a. ed.). Tucson, EUA: Lawyers \& Judges Publishing Company Inc.

Elvik, R. e T. Vaa (2004) The Handbook of Road Safety Measures. Oxford, Reino Unido: Elsevier Ltd..

Evans, L. (2004) Traffic safety (2a . ed.). Science Serving Society, Bloomfield Hills, EUA.

Falk, B. e H. Montgomery (2007) Developing traffic safety interventions from conceptions of risks and accidents. Transportation Research Part F. v. 10, n. 5, p. 411-427.

Falk, B. e H. Montgomery (2009) Promoting traffic safety among young male drivers by means of elaboration-based interventions. Transportation Research Part F. v. 12, n. 1, p. 1-11.

Ferguson, S.A.; A. P. Hardy e A. F. Williams (2003) Content analysis of television advertising for cars and minivans: 1983-1988. Accident Analysis and Prevention, v. 35, n. 6, p. 825-831.

Ferraz, A.C.P; A. A. Raia Jr. e B. S. Bezerra (2008) Segurança no trânsito. NEST, São Carlos.

GRSP (2007) Drinking and Driving: a road safety manual for decisionmakers and practitioners. Global Road Safety Partnership, Geneva.

Hoffmann, M.H. (2005) Comportamento do condutor e fenômenos psicológicos. Psicologia: Pesquisa \& Trânsito, v. 1, n. 1, p. 17-24.
Ker, K.; I. G. Roberts; T. Collier; F. R. Beyer; F. Bunn e C. Frost (2003) Post-licence driver education for the prevention of road traffic crashes. Cochrane Database of Systematic Reviews. n. 3.

Koornstra, M. J. (2009) Risk-adaptation theory. Transportation Research Part F, v. 12, n. 1, p. 77-90.

Kume, L. (2007) É possivel reduzir as mortes no trânsito?: o efeito do novo Código Brasileiro de Trânsito. Dissertação (mestrado). Escola de Pós-Graduação em Economia, Fundação Getúlio Vargas. Rio de Janeiro.

Laapotti, S. (2005) What are young female drivers made of? Differences in driving behavior and attitudes of young women and men in Finland. Proceedings of Transportation Research Board conference. Research on women's issues in transportation, technical papers, v. 2, p. 148-154, Chicago, IL: TRB.

Langford, J. e S. Koppel (2006) Epidemiology of older driver crashes Identifying older driver risk factors and exposure patterns. Transportation Research Part F, v. 9, n. 5, p. 309-321.

Mattar, F.N. (2005) Pesquisa de marketing: metodologia e planejamento (6a. ed.). Atlas, São Paulo. 350p.

Mayhew, D.R.; H. M. Simpson e A. Pak (2003) Changes in collision rates among novice drivers during the first months of driving. Accident Analysis and Prevention, v. 35, n. 5, p. 683-691.

Mayhew, D.R; H. M. Simpson e A. Robinson (2002) The safety value of driver education an training. Injury Prevention. v. 8, supl. 2, p. ii3-ii8.

Merat, N; V. Anttila e J. Luoma (2005) Comparing the driving performance of average and older drivers: The effect of surrogate invehicle information systems. Transportation Research Part F, v. 8, n. 2, p. 147-166

NHTSA (2000) Aggressive driving enforcement: strategies for implementing best practices. Washington, DC: National Highway Traffc Safety Administration, 2000. Disponível em: <http://www.nhtsa. dot.gov/people/injury/enforce/aggressdrivers/aggenforce/index. html $>$ (Acessado em 29/11/2009).

Nyberg, A. e N. P. Gregersen (2007) Practicing for and performance on drivers license tests in relation to gender differences in crash involvement among novice drivers. Journal of Safety Research. v. 38 , n. 1, p. $71-80$.

Ogden, K.W. (1996) Safer Roads: A guide to road safety engineering. Ashgate, Burlington, EUA. 516p.

Özkan, T. e T. Lajunen (2006) What causes the differences in driving between young men and women? The effects of gender roles and sex on young drivers' driving behaviour and self-assessment of skills. Transportation Research Part F, v. 9, n. 4, p. 269-277.

Prato, C.G.; T. Lotan e T. Toledo (2009) Intra-familial transmission of driving behavior: evidence from in-vehicle data recorders. Transportation Research Record, v. 2138, p. 54-65.

Redelmeier, D.A.; R. J. Tibshirani e L. Evans (2003) Traffic-law enforcement and risk of death from motor-vehicle crashes: case-crossover study. The Lancet, v. 361, n. 9376, p. 2177-2182.

Ribeiro, J.L.D e M. E. Echeveste (1998) Dimensionamento da amostra em pesquisa de satisfação de clients. Anais do XVIII ENEGEP, Niterói.

Rio Grande do Sul (2001) Lei 11.644, de 28 de junho de 2001. Publicada no Diário Oficial do Estado do Rio Grande do Sul em 20 de junho de 2001 .

Shinar, D. (2007) Traffic safety and human behavior. Elsevier, Amsterdam, Holanda.

Tronsmoen, T. (2008) Associations between self-assessment of driving ability, driver training and crash involvement among young drivers. Transportation Research Part F, v. 11, n. 5, p. 334-346.

Ulleberg, P. (2001) Personality subtypes of young drivers. Relationship to risk-taking preferences, accident involvement, and response to a traffic safety campaign. Transportation Research Part F, v. 4, n 4, p. 279-297.

Viana, M.B. (2005) Código de Trânsito Brasileiro: efeitos nas taxas de vitimas de acidentes. Brasília: Câmara dos Deputados. Disponível em <http://bd.camara.gov.br/bd/handle/bdcamara/1486> (Acessado em $3 / 2 / 2010)$

Yagil, D. (1998a) Gender and age-related differences in attitudes toward traffic laws and traffic violations. Transportation Research Part $F$, v. 1, n. 2, p. $123-135$

Yagil, D. (1998b) Instrumental and normative motives for compliance with traffic laws among young and older drivers. Accident Analysis and Prevention, v. 30, n. 4, p. 417-424. 